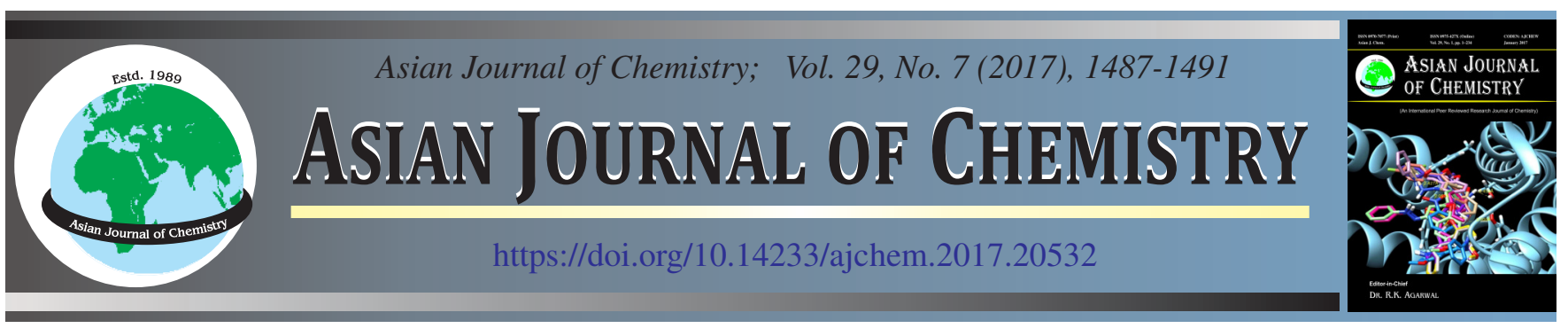

\title{
Theoretical Study of Reaction Mechanism between \\ N,N-Dimethyl acrylamide and Carbazole Derivatives Catalyzed by Palladium(II)
}

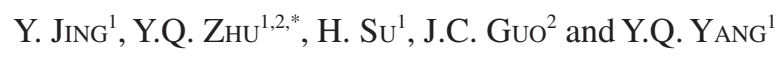

${ }^{1}$ School of Chemistry and Chemical Engineering, Southwest Petroleum University, Chengdu 610500, P.R. China

${ }^{2}$ State Key Laboratory of Oil and Gas Reservoir Geology and Exploitation, Southwest Petroleum University, Chengdu 610500, P.R. China

*Corresponding author: Tel: +86 28 83037366; E-mail: zhuline518@163.com; 846441572@qq.com

Received: 21 January 2017;

Accepted: 23 March 2017;

Published online: 13 May 2017;

AJC-18379

\begin{abstract}
The reaction mechanism between $\mathrm{N}, \mathrm{N}$-dimethyl acrylamide and carbazole derivatives catalyzed by palladium acetate has been investigated by using density functional theory (DFT) with M06 functional. The computational results indicate that the reaction without catalyst reacts via one pathway with a high energy barrier of $254.57 \mathrm{~kJ} \mathrm{~mol}^{-1}$. While the reaction can happen through two approaches to generate the same product with the existence of palladium acetate catalysis. Furthermore, the catalyst is better to depart from the product as a whole part. And the determining step of dominant pathway in the Pd-catalyzed reaction is the formation of C-N bond which has an energy barrier of $137.91 \mathrm{~kJ} \mathrm{~mol}^{-1}$. As a result, palladium catalyst not only changes the reaction mechanism, but also decreases the energy barrier significantly which stimulated the reaction well. This study illustrates the reaction mechanism and has a guiding significance for new catalysts designing.
\end{abstract}

Keywords: DFT calculation, Carbazole derivatives, Palladium acetate, Catalyst, Reaction mechanism.

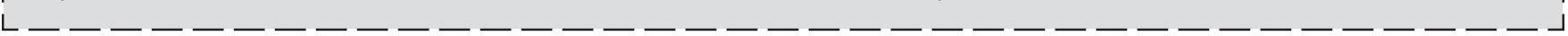

\section{INTRODUCTION}

Carbon-hydrogen bond functionalization reaction is a highly atom-economical approach for the site-selective formation of C-N bond [1-3]. As a most valuable tool of activating the unreactive carbon-hydrogen bond, transition metal-catalyzed reactions have been extensively and systematically investigated [4,5]. Among transition metals, palladium shows an excellent catalytic performance for appropriate coordinating with all kinds of ligands, such as N-heterocyclic carbenes [6-8] and acetate [9-12] and it has become one of the most effective transition metal catalysts [13-15]. Palladium catalysts have been widely used in C-N coupling reactions, like Suzuki-Miyaura reaction [16-18], Heck-Mizoroki reaction [19-22], Stille reaction [23-27] and Sonogashira reaction [28-30]. Wang et al. [31] studied the reaction of $\mathrm{N}$-methoxybenzamides and methyl acrylate by palladium-catalyzed and found that the reaction could achieve a high yield under relative mild circumstances. Zhang et al. [32] studied amination of carbon-hydrogen bond under the existence of palladium catalyst, which provides versatile approaches to ammoniate aromatic ring. Buchwald et al. [33] studied the formation mechanism of carbon-nitrogen and carbon-oxygen bond which catalyzed by palladium. Takeda et al. [34] studied palladiumcatalyzed reactions between ethylenes and carbazole. According to the issue, a plausible mechanism of the reaction is
Pd(II) center coordinated with styrene and subsequent activated ethylene and finally the acetic acid deprives from the product one by one as well as the palladium atom.

In a reaction the palladium catalyst can deprive from product not only as separated acetic acid molecule and palladium atom but also a whole part. To make the reaction mechanism between N,N-dimethyl acrylamide and carbazole derivatives, this article illustrated a theoretical study on Pd-catalyzed reaction between $\mathrm{N}, \mathrm{N}$-dimethyl acrylamide and carbazole derivatives.

\section{COMPUTATIONAL METHODS}

Gaussian 09 program [35] was employed for all calculations which based on the fundamental laws of quantum mechanism give numerous of important information. At the very beginning, we studied the reaction with the hybrid B3LYP [36] functional and the effective core potential basis set LANL2DZ [37] for metal element and 6-31G** [38-41] basis set for non-metal elements. Geometries of every molecules are optimized by M06 [42] functional with LANL2TZ [37,43] basis set for palladium atom and 6-31G** basis set for other nonmetal atoms. In this paper, vibration frequencies were calculated to get thermal corrections and identify transition states of every stationary point and the natural bond orbital (NBO) $[44,45]$ analysis was applied to evaluate the Wiberg 

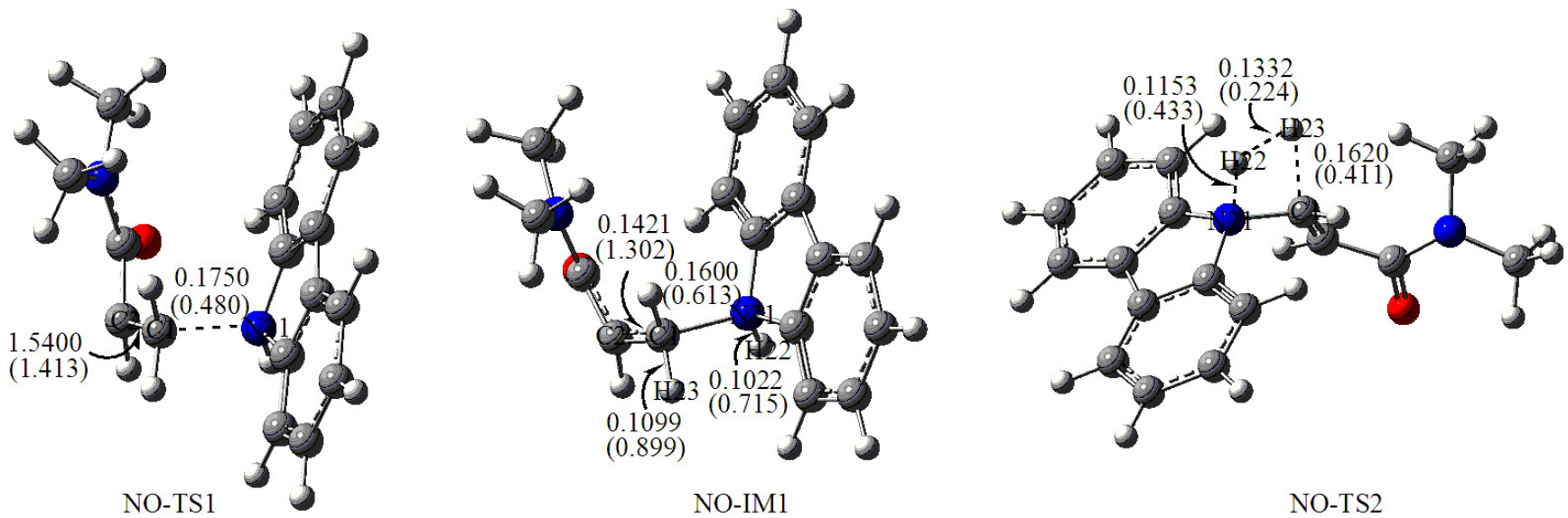

Fig. 1. Optimized geometry parameters and the Wiberg bond indices (in parenthesis) at the M06/6-31G** level (bond length in nm)

bond indices. All these calculations were carried out at the same level. The MOL files of corresponding structures at every stationary points which optimized by M06 functional were presented in the supplementary data. For the reaction, the calculations of M06 and B3LYP methods achieved a same result. Therefore, this study focused on results calculated with M06 functional to discuss the mechanism of the reaction between $\mathrm{N}, \mathrm{N}$-dimethyl acrylamide and carbazole derivatives.

\section{RESULTS AND DISCUSSION}

Mechanism of the reaction without catalyst: Without catalyst, the reaction occurred through just one pathway, which includes two steps. Figs. 1 and 2 show molecular parameters (optimized configurations, bond lengths, atom labels and the Wiberg bond indices) and free energies respectively.

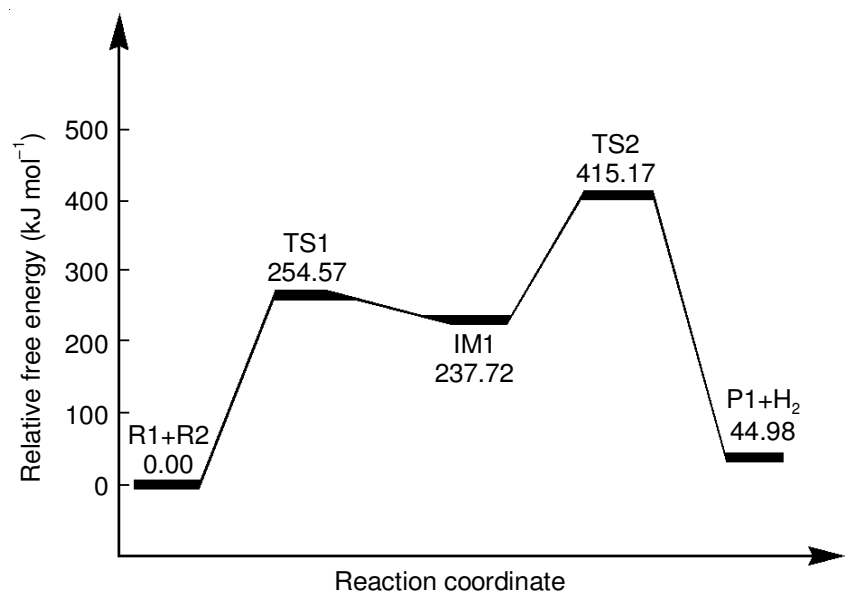

Fig. 2. Schematic relative free energy profile for the reaction calculated at the $\mathrm{M} 06 / 6-31 \mathrm{G}^{* *}$ level

Firstly, the intermediate NO-IM1 was formed by the nitrogen atom in carbazole derivatives attacking the carbon atom in N,N-dimethyl acrylamide through NO-TS1 the transition state of the reaction. The distance between $\mathrm{C}_{1}$ and $\mathrm{N}_{21}$ atoms shortened from $0.1750 \mathrm{~nm}$ to $0.1600 \mathrm{~nm}$ while the Wiberg bond index increased from 0.480 to 0.613 during this process. These changes indicate that the $\mathrm{C}_{1}-\mathrm{N}_{21}$ bond has come into being. This process is hard to take place without catalyst due to the high energy barrier of $254.57 \mathrm{~kJ} \mathrm{~mol}^{-1}$. Secondly, the bond length of $\mathrm{N}_{21}-\mathrm{H}_{22}$ increased from $0.1022 \mathrm{~nm}$ to $0.1153 \mathrm{~nm}$ and the Wiberg bond index decreased from 0.715 to 0.433 during the process of NO-IM1 to NO-TS2, which indicates that the $\mathrm{N}_{21}-\mathrm{H}_{22}$ bond is breaking. There were similar tendencies happening in the $\mathrm{C}_{1}-\mathrm{H}_{23}$ bond that the bond length have been increased from $0.1099 \mathrm{~nm}$ in NO-IM1 to $0.1620 \mathrm{~nm}$ in NO-TS2. But the length of the $\mathrm{H}_{22}-\mathrm{H}_{23}$ bond decreased to $0.1332 \mathrm{~nm}$ and the Wiberg bond index increased to 0.224 in NO-TS2 at the same time. The forming process of $\mathrm{H}_{22}-\mathrm{H}_{23}$ bond in NO-TS2 needs a relative high energy barrier of $177.45 \mathrm{~kJ} \mathrm{~mol}^{-1}$. As shown in Fig. 2, the determining step of the reaction without catalyst is proved to be the formation of the $\mathrm{C}-\mathrm{N}$ bond with the energy barrier of $254.57 \mathrm{~kJ} \mathrm{~mol}^{-1}$. That indicates the reaction without catalysts is kind of tough to react with such a high energy barrier.

Mechanism of the Pd-catalyzed reaction by palladium acetate: The reaction could take place through two possible pathways with the palladium acetate catalyst. Figs. 3 and 4 show molecular parameters (optimized configurations, bond lengths, atom labels and the Wiberg bond indices) and free energies respectively.

As shown in Figs. 3 and 4, the first pathway involves five steps. The first step is that the palladium acetate coupled with the $\mathrm{C}_{1}=\mathrm{C}_{2}$ double bond in the reactant $\mathrm{R} 1$ and generated the intermediate IM1. In this procedure, the distances between palladium atom and $C_{1}$ and $C_{2}$ atoms decreased to $0.2159 \mathrm{~nm}$ and $0.2179 \mathrm{~nm}$ and the Wiberg bond indices increased to 0.433 and 0.406 in IM1, respectively. These indicate that there is an interaction between the catalyst and the reactant. Due to the coupling, the free energy of the reaction reduced to $138.81 \mathrm{~kJ}$ moll $^{-1}$, which means a strong interaction between $\mathrm{Pd}_{17}$ atom and $C_{1}=C_{2}$ bond happened. And this interaction made the strength of $\mathrm{C}_{1}=\mathrm{C}_{2}$ bond substantially weakened and turned the $\mathrm{C}_{1}=\mathrm{C}_{2}$ bond into a single bond. Changes of the bond lengths and Wiberg bond indices demonstrate that $\pi$-electrons transferred from $\mathrm{C}_{1}=\mathrm{C}_{2}$ bond to the empty $d$-orbital of palladium atom, which facilitated the chemical activity of $\mathrm{C}_{1}-\mathrm{C}_{2}$ bond. In the second step, the $\mathrm{N}_{21}$ atom in $\mathrm{R} 2$ attacked the $\mathrm{C}_{1}$ atom in IM1 and generated the intermediate (IM2) though the transition state (TS1). In this process, the length of the $\mathrm{C}_{1}-\mathrm{N}_{21}$ bond decreased from $0.2144 \mathrm{~nm}$ in TS1 to $0.1529 \mathrm{~nm}$ in IM2 and the Wiberg bond index increased from 0.359 to 0.860 that means the formation of the $\mathrm{C}_{1}-\mathrm{N}_{21}$ bond. Although this process 

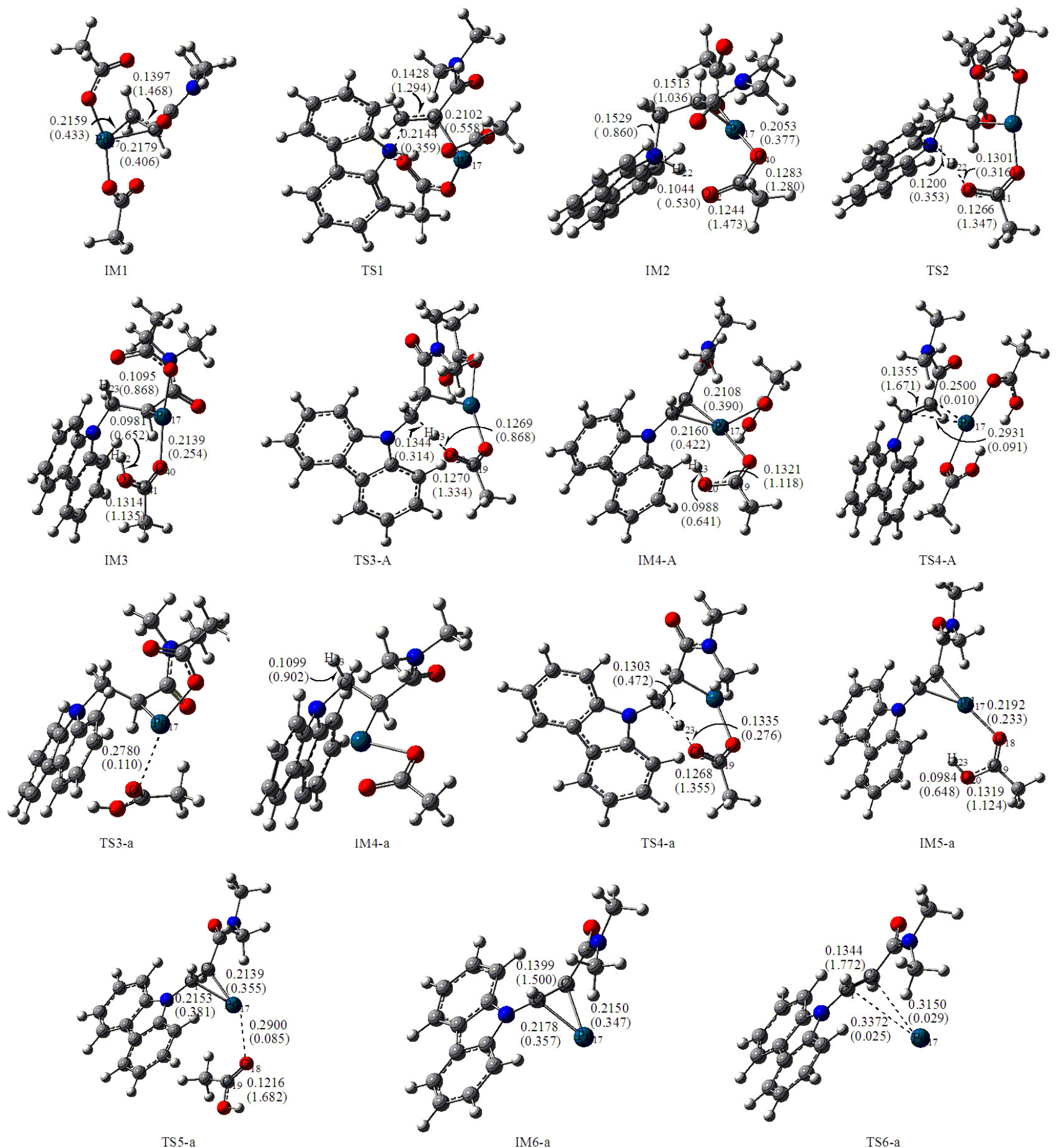

Fig. 3. Optimized geometry parameters and the Wiberg bond indices (in parenthesis) at the M06/(Pd:LANL2TZ;C,H,O,N:6-31G**) level (bond length in $\mathrm{nm}$ )

has a relative high energy barrier of $137.91 \mathrm{~kJ} \mathrm{~mol}^{-1}$, as illustrated in Fig. 4, the exothermic heat of the formation IM1 is sufficient to promote the reaction. The third step is the transformation of $\mathrm{H}_{22}$ atom from $\mathrm{N}_{21}$ atom to $\mathrm{O}_{42}$ atom. The bond length of the $\mathrm{N}_{21}-\mathrm{H}_{22}$ bond increased from $0.1044 \mathrm{~nm}$ in IM2 to $0.1200 \mathrm{~nm}$ in TS2 and the Wiberg bond index dropped from 0.530 to 0.353 . The distance of $\mathrm{O}_{42}-\mathrm{H}_{22}$ bond reduced from $0.1301 \mathrm{~nm}$ in TS2 to $0.0981 \mathrm{~nm}$ in IM3 and the Wiberg bond index increased from 0.316 to 0.652 at the same time. Changes of these two bonds show the break of the $\mathrm{N}_{21}-\mathrm{H}_{22}$ bond and the formation of the $\mathrm{O}_{42}-\mathrm{H}_{22}$ bond. And then the transformation of $\mathrm{H}_{22}$ was completed. The fourth step is that the $\mathrm{H}_{23}$ transferred from $\mathrm{C}_{1}$ to $\mathrm{O}_{20}$. The bond length of $\mathrm{C}_{1}-\mathrm{H}_{23}$ is increased from $0.1095 \mathrm{~nm}$ in IM3 to $0.1344 \mathrm{~nm}$ in TS3-A and the Wiberg index dropped from 0.868 to 0.314 , which signifies that the $\mathrm{C}_{1}-\mathrm{H}_{23}$ bond is gradually breaking. And the bond length of the $\mathrm{O}_{20}-\mathrm{H}_{23}$ bond reduced from $0.1269 \mathrm{~nm}$ in TS3-A to 0.0988 $\mathrm{nm}$ in IM4-A and the Wiberg index decreased from 0.868 in 


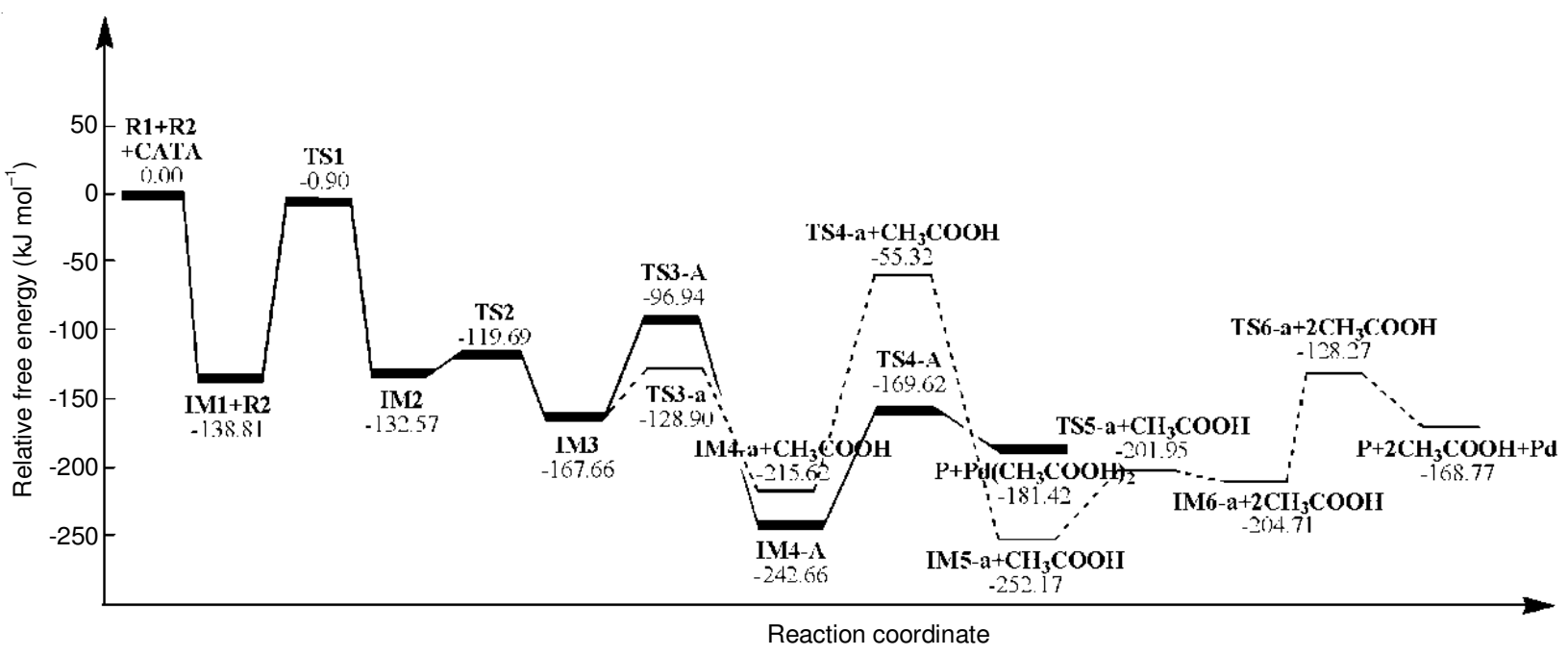

Fig. 4. Schematic potential energy profile for the reaction calculated at the M06/(Pd: LANL2TZ; C,H,O,N: 6-31G**) level

TS3-A to 0.641 in IM4-A suggested the formation of the $\mathrm{O}_{20}-\mathrm{H}_{23}$ bond. The $\mathrm{H}_{23}$ transformation needs to surmount an energy barrier of $70.72 \mathrm{~kJ} \mathrm{~mol}^{-1}$. In the fifth step, the catalyst dropped off from the product. The bond lengths of $\mathrm{C}_{1}-\mathrm{Pd}_{17}$ and $\mathrm{C}_{2}-\mathrm{Pd}_{17}$ increased from $0.2160 \mathrm{~nm}$ and $0.2108 \mathrm{~nm}$ in IM4A to $0.2931 \mathrm{~nm}$ and $0.2500 \mathrm{~nm}$ in TS4-A. The Wiberg bond indices of these two bonds shortened from 0.422 and 0.390 in IM4-A to 0.091 and 0.010 in TS4-A. These changes indicate that $\mathrm{C}_{1}-\mathrm{Pd}_{17}$ and $\mathrm{C}_{2}-\mathrm{Pd}_{17}$ bonds are breaking and the palladium acetate is leaving. The energy barrier of this procedure is 73.04 $\mathrm{kJ} \mathrm{mol}^{-1}$. Comparing these five procedures, the formation of the $\mathrm{C}-\mathrm{N}$ bond which is the determining step has the highest energy barrier.

As shown in Figs. 3 and 4, the second pathway is that acetate molecules and the palladium atom of the catalyst departing from the product one by one. This pathway involves seven steps, in which the first three steps have no difference with the first pathway. But in the fourth step, one of the acetate molecules departed from IM3. In TS3-a, the bond length of the $\mathrm{O}_{40}-\mathrm{Pd}_{17}$ bond increased to $0.2780 \mathrm{~nm}$ while the Wiberg bond index decreased to 0.110 that indicate the bond is breaking. The energy barrier of this step is $38.76 \mathrm{~kJ} \mathrm{~mol}^{-1}$. The fifth step is that the $\mathrm{H}_{23}$ transferred from $\mathrm{C}_{1}$ atom to $\mathrm{O}_{20}$ atom. The bond length of the $\mathrm{C}_{1}-\mathrm{H}_{23}$ bond increased from 0.1099 $\mathrm{nm}$ in IM4-a to $0.1303 \mathrm{~nm}$ TS4-a and the Wiberg bond index decreased from 0.902 into 0.472 , respectively. The Wiberg bond index of the $\mathrm{H}_{23}-\mathrm{O}_{20}$ bond increased from 0.276 in TS4a to 0.648 in IM5-a and bond length shortened from 0.1335 $\mathrm{nm}$ to $0.0984 \mathrm{~nm}$. These data demonstrate that the $\mathrm{H}_{23}-\mathrm{O}_{20}$ bond is gradually forming as well as the $\mathrm{C}_{1}-\mathrm{H}_{23}$ bond is breaking. Fig. 4 presented that the transformation of hydrogen $\left(\mathrm{H}_{23}\right)$ required an energy barrier of $160.30 \mathrm{~kJ} \mathrm{~mol}^{-1}$. Another acetate molecule departed from IM5-a in the sixth step. The distance between $\mathrm{Pd}_{17}$ and $\mathrm{O}_{18}$ became longer and longer till 0.2900 $\mathrm{nm}$ whereas the Wiberg bond index dropped to 0.085 in TS5-a. A small Wiberg bond index demonstrates that one of the acetate molecules is leaving from the palladium atom. It is not difficult for acetate molecule to leave, on account of the relative low energy barrier, which is just $50.22 \mathrm{~kJ} \mathrm{~mol}^{-1}$ in this step. And the palladium atom departed from the product finally. The bond lengths of $\mathrm{C}_{1}-\mathrm{Pd}_{17}$ and $\mathrm{C}_{2}-\mathrm{Pd}_{17}$ increase from $0.2178 \mathrm{~nm}$ and $0.2150 \mathrm{~nm}$ in IM6-a to $0.3372 \mathrm{~nm}$ and $0.3150 \mathrm{~nm}$ in TS6-a, which indicate the departure of the $\mathrm{Pd}_{17}$. And the palladium atom seems like hard to depart from the product with the energy barrier of $76.44 \mathrm{~kJ} \mathrm{~mol}^{-1}$. Comparing with energy barriers of seven processes, the transformation of $\mathrm{H}_{23}$ is the determining step of this pathway and it has the highest energy barrier of $160.30 \mathrm{~kJ} \mathrm{~mol}^{-1}$.

From Figs. 2 and 4, it can be seen that the reaction with catalyst sharply decreases the energy barrier of the determining step by $116.66 \mathrm{~kJ} \mathrm{~mol}^{-1}$ compared with the one without catalyst. And the barrier of the dominant pathway in the catalyzed reaction is 22.39 lower than the other pathway.

\section{Conclusion}

M06 functional with LANL2TZ for metal element and 6$31 \mathrm{G}^{* *}$ basis set for non-metal elements was applied to study the reaction mechanism between $\mathrm{N}, \mathrm{N}$-dimethylacrylamide and carbazole derivatives. The reaction without catalyst occurs through just one pathway and the determining step which has an energy barrier of $254.57 \mathrm{~kJ} \mathrm{~mol}^{-1}$ is the formation of the C-N bond. However, the Pd-catalyzed reaction can react via two pathways. The determining step of each pathway is the formation of the C-N bond with a free energy barrier of $137.91 \mathrm{~kJ}$ $\mathrm{mol}^{-1}$ and the transformation of the $\mathrm{H}_{23}$ with a free energy barrier of $160.30 \mathrm{~kJ} \mathrm{~mol}^{-1}$. The palladium acetate alters the reaction mechanism and significantly decreases the free energy barrier of the key step. Furthermore, the catalyst deprive from product integrally was superior to depart acetate molecules and palladium atom separately. This study has illustrated the reaction mechanism of the title reaction and it has a reference value for designing catalysts for similar reactions.

\section{ACKNOWLEDGEMENTS}

This work was financially supported by the Open Fund (No.: PLN1124) of State Key Laboratory of Oil and Gas Reservoir Geology and Exploitation, Southwest Petroleum University. Chengdu, P.R. China 


\section{REFERENCES}

1. R. Xia, H.Y. Niu, G.R. Qu and H.M. Guo, Org. Lett., 14, 5546 (2012); https://doi.org/10.1021/o1302640e.

2. Y. Wang, D. Wei, Y. Wang, W. Zhang and M. Tang, ACS Catal., 6, 279 (2016); https://doi.org/10.1021/acscatal.5b01710

3. S. Pan and T. Shibata, ACS Catal., 3, 704 (2013); https://doi.org/10.1021/cs400066q.

4. C.-L. Sun, H. Li, D.-G. Yu, M. Yu, X. Zhou, X.-Y. Lu, K. Huang, S.-F. Zheng, B.-J. Li and Z.-J. Shi, Nat. Chem., 2, 1044 (2010); https://doi.org/10.1038/nchem.862.

5. Y.Q. Zhu, H. Su, J.L. Tang and Y.Q. Yang, Comput. Theor. Chem., 1068, 47 (2015);

https://doi.org/10.1016/j.comptc.2015.06.010.

6. C. Valente, S. Calimsiz, K.H. Hoi, D. Mallik, M. Sayah and M.G. Organ, Angew. Chem. Int. Ed., 51, 3314 (2012); https://doi.org/10.1002/anie.201106131.

7. A. Pommella, G. Tomaiuolo, A. Chartoire, S. Caserta, G. Toscano, S.P Nolan and S. Guido, Chem. Eng. J., 223, 578 (2013); https://doi.org/10.1016/j.cej.2013.03.070.

8. E.K. Bullough, M.A. Little and C.E. Willans, J. Organomet., 32, 570 (2013); https://doi.org/10.1021/om301085s.

9. A. Petit, J. Flygare, A.T. Miller, G. Winkel and D.H. Ess, Org. Lett., 14, 3680 (2012); https://doi.org/10.1021/ol301521n

10. S. Ye, H. Wang, Q. Xiao, Q. Ding and J. Wu, Adv. Synth. Catal., 356, 3225 (2014); https://doi.org/10.1002/adsc.201400334.

11. B. Lopez, A. Rodriguez, D. Santos, J. Albert, X. Ariza, J. Garcia and J. Granell, Chem. Commun., 47, 1054 (2011) https://doi.org/10.1039/C0CC03478A.

12. L. Chen, C. Bruneau, P.H. Dixneuf and H. Doucet, Tetrahedron, 69, 4381 (2013); https://doi.org/10.1016/j.tet.2012.12.061.

13. W. Liu, H. Cao, H. Zhang, H. Zhang, K.H. Chung, C. He, H. Wang, F.Y. Kwong and A. Lei, J. Am. Chem. Soc., 132, 16737 (2010); https://doi.org/10.1021/ja103050x.

14. A.J. Hickman and M.S. Sanford, Nature, 484, 177 (2012); https://doi.org/10.1038/nature11008.

15. T.W. Lyons and M.S. Sanford, Chem. Rev., 110, 1147 (2010); https://doi.org/10.1021/cr900184e.

16. F. Liu, G. Feng, M. Lin, C. Wang, B. Hu and C. Qi, J. Colloid Interface Sci., 435, 83 (2014); https://doi.org/10.1016/j.jcis.2014.08.010.

17. N.C. Bruno, M.T. Tudge and S.L. Buchwald, Chem. Sci., 4, 916 (2013); https://doi.org/10.1039/C2SC20903A.

18. M. Sharif, K. Shoaib, S. Ahmed, J. Iqbal, Z.A. Abilov, A. Spannenberg and P. Langer, Tetrahedron Lett., 57, 3060 (2016); https://doi.org/10.1016/j.tetlet.2016.05.041.

19. Z. Mandegani, M. Asadi, Z. Asadi, A. Mohajeri, N. Iranpoor and A. Omidvar, Green Chem., 17, 3326 (2015); https://doi.org/10.1039/C5GC00616C.

20. A.K. Rathi, M.B. Gawande, J. Pechousek, J. Tucek, C. Aparicio, M. Petr, O. Tomanec, R. Krikavova, Z. Travnicek, R.S. Varma and R. Zboril, Green Chem., 18, 2363 (2016); https://doi.org/10.1039/C5GC02264A.

21. A. Biffis, M. Zecca and M. Basato, J. Mol. Catal. Chem., 173, 249 (2001); https://doi.org/10.1016/S1381-1169(01)00153-4.

22. Z. Yang and J. Zhou, J. Am. Chem. Soc., 134, 11833 (2012); https://doi.org/10.1021/ja304099j.

23. C. Cordovilla, C. Bartolomé, J.M. Martínez-Ilarduya and P. Espinet, ACS Catal., 5, 3040 (2015); https://doi.org/10.1021/acscatal.5b00448.

24. S.M. McAfee, J.S.J. McCahill, C.M. Macaulay, A.D. Hendsbee and G.C. Welch, RSC Adv., 5, 26097 (2015); https://doi.org/10.1039/C5RA02468D.
25. M. Hervé, G. Lefèvre, E.A. Mitchell, B.U. Maes and A. Jutand, Chem. Eur. J., 21, 18401 (2015); https://doi.org/10.1002/chem.201503309.

26. N.P. Cheval, A. Dikova, A. Blanc, J.M. Weibel and P. Pale, Chem. Eur. J., 19, 8765 (2013) https://doi.org/10.1002/chem.201300127.

27. A. Jutand and G. Lefèvre, in ed.: J. Mortier, Transition Metal Mediated Carbon-Carbon Cross Coupling, In: Arene Chemistry: Reaction Mechanisms and Methods for Aromatic Compounds, p. 511 (2016).

28. J.D. Way, C. Bergman and F. Wuest, Chem. Commun., 51, 3838 (2015); https://doi.org/10.1039/C5CC00182J.

29. R. Chinchilla and C. Nájera, in eds.: B.M. Trost and C.-J. Li, The Sonogashira Reaction, In: Modern Alkyne Chemistry-Catalytic and Atom-Economic Transformations, Wiley-VCH, Weinheim, Chap. 10, pp. 269-297 (2014).

30. J. Chung, J. Kim, Y. Jang, S. Byun, T. Hyeon and B.M. Kim, Synfacts, 9, 1246 (2013); https://doi.org/10.1055/s-0033-1340027.

31. D.D. Li, T.T. Yuan and G.W. Wang, Chem. Commun., 47, 12789 (2011); https://doi.org/10.1039/c1cc15897j.

32. K. Sun, Y. Li, T. Xiong, J. Zhang and Q. Zhang, J. Am. Chem. Soc., 133, 1694 (2011); https://doi.org/10.1021/ja1101695.

33. S. Ueda, S. Ali, B.P. Fors and S.L. Buchwald, J. Org. Chem., 77, 2543 (2012); https://doi.org/10.1021/jo202537e.

34. D. Takeda, K. Hirano, T. Satoh and M. Miura, Org. Lett., 15, 1242 (2013); https://doi.org/10.1021/ol4001697.

35. M.J. Frisch, G.W. Trucks, H.B. Schlegel, G.E. Scuseria, M.A. Robb, J.R. Cheeseman, G. Scalmani, V. Barone, B. Mennucci, G.A. Petersson, H. Nakatsuji, M. Caricato, X. Li, H.P. Hratchian, A.F. Izmaylov, J. Bloino, G. Zheng, J.L. Sonnenberg, M. Hada, M. Ehara, K. Toyota, R. Fukuda, J. Hasegawa, M. Ishida, T. Nakajima, Y. Honda, O. Kitao, H. Nakai, T. Vreven, J.A. Montgomery Jr., J.E. Peralta, F. Ogliaro, M. Bearpark, J.J. Heyd, E. Brothers, K.N. Kudin, V.N. Staroverov, R. Kobayashi, J. Normand, K. Raghavachari, A. Rendell, J.C. Burant, S.S. Iyengar, J. Tomasi, M. Cossi, N. Rega, J.M. Millam, M. Klene, J.E. Knox, J.B. Cross, V. Bakken, C. Adamo, J. Jaramillo, R. Gomperts, R.E. Stratmann, O. Yazyev, J.A. Austin, R. Cammi, C. Pomelli, J.W. Ochterski, R.L. Martin, K. Morokuma, V.G. Zakrzewski, G.A. Voth, P. Salvador, J.J. Dannenberg, S. Dapprich, A.D. Daniels, O. Farkas, J.B. Foresman, J.V. Ortiz, J. Cioslowski and D.J. Fox, Gaussian 09, Revision D.01; Gaussian Inc: Wallingford, CT (2010).

36. J.P. Foster and F. Weinhold, J. Am. Chem. Soc., 102, 7211 (1980); https://doi.org/10.1021/ja00544a007.

37. P.J. Hay and W.R. Wadt, J. Chem. Phys., 82, 299 (1985); https://doi.org/10.1063/1.448975.

38. R.H.W.J. Ditchfield, W.J. Hehre and J.A. Pople, J. Chem. Phys., 54, 724 (1971); https://doi.org/10.1063/1.1674902.

39. W.J. Hehre, R. Ditchfield and J.A. Pople, J. Chem. Phys., 56, 2257 (1972); https://doi.org/10.1063/1.1677527.

40. V.A. Rassolov, M.A. Ratner, J.A. Pople, P.C. Redfern and L.A. Curtiss, J. Comput. Chem., 22, 976 (2001); https://doi.org/10.1002/jcc. 1058 .

41. A. Petersson, A. Bennett, T.G. Tensfeldt, M.A. Al-Laham, W.A. Shirley and J. Mantzaris, J. Chem. Phys., 89, 2193 (1988); https://doi.org/10.1063/1.455064.

42. Y. Zhao and D.G. Truhlar, Theor. Chem. Acc., 120, 215 (2008); https://doi.org/10.1007/s00214-007-0310-x.

43. L.E. Roy, P.J. Hay and R.L. Martin, J. Chem. Theory Comput., 4, 1029 (2008); https://doi.org/10.1021/ct8000409.

44. J.E. Carpenter and F. Weinhold, J. Mol. Struct. THEOCHEM, 169, 41 (1988); https://doi.org/10.1016/0166-1280(88)80248-3.

45. A.E. Reed, L.A. Curtiss and F. Weinhold, Chem. Rev., 88, 899 (1988); https://doi.org/10.1021/cr00088a005. 